\title{
Disparity in motorcycle helmet use in Thailand
}

\author{
Paibul Suriyawongpaisa ${ }^{1 *}$, Ammarin Thakkinstian ${ }^{2}$, Aratta Rangpueng ${ }^{3}$, Piyapong Jiwattanakulpaisarn ${ }^{4}$ \\ and Pimpa Techakamolsuk ${ }^{3}$
}

\begin{abstract}
The dispersion of motorcycle related injuries and deaths might be a result of disparity in motorcycle helmet use. This study uses national roadside survey data, injury sentinel surveillance data and other national data sets in 2010 of Thailand, a country with high mortality related to motorcycle injuries, to explore the disparity in helmet use, explanatory factors of the disparity. It also assessed potential agreement and correlation between helmet use rate reported by the roadside survey and the injury sentinel surveillance. This report revealed helmet use rate of $43.7 \%$ (95\% Cl:43.6,43.9) nationwide with the highest rate $(81.8 \%$; $95 \% \mathrm{Cl}: 44.0,46.4)$ in Bangkok. Helmet use rate in drivers (53.3\%; 95\% Cl: 53.2,53.8) was 2.5 times higher than that in passengers (19.3\%; 95\% Cl:18.9,19.7). In relative terms (highest-to-lowest ratio,HLR), geographical disparity in helmet use was found to be higher in passengers (HLR=28.5). Law enforcement activities as indicated by the conviction rate of motorcyclists were significantly associated with the helmet use rate (spline regression coefficient $=3.90,95 \% \mathrm{Cl}: 0.48,7.33$ ). Together with the finding of HLR for conviction rate of 87.24 , it is suggested that more equitable improvement in helmet use could be achieved by more equitable distribution of the police force. Finally, we found poor correlation $(r=0.01 ; p$ value $=0.76)$ and no agreement (difference $=34.29 \%$; 95\% Cl:13.48\%, 55.09\%) between roadside survey and injury sentinel surveillance in estimating helmet use rate. These findings should be considered a warning for employing injury surveillance to monitor policy implementation of helmet use.
\end{abstract}

Keywords: Inequity, Helmet use, Resource allocation, Law enforcement

\section{Background}

Globally, road traffic injuries (RTIs) have been increasing in many regions of the world in contrast to declining trends in highly motorized countries [1]. The majority of RTI related deaths occur in low-income and middleincome countries. Within country, the dispersion of RTIs has also been reported across age groups, gender, economic status and areas [2,3]. Differences in RTIs across areas might reflect lack of access to or scarcity of local goods, services, resources and amenities (area material deprivation) in specific areas as shown by a study investigating the association between area material deprivation/urbanicity and young unlicensed driver involvement in fatal crashes in the United States [4]. At the area level, accumulated evidence supports an association between economic deprivation and low population density and severe RTIs after taking account for the

\footnotetext{
*Correspondence: paibulss@gmail.com

'Department of Community Medicine, Faculty of Medicine, Ramathibodi Hospital, Mahidol University, Rama VI, Ratchathevee 10400, Thailand Full list of author information is available at the end of the article
}

adult or total population of motor vehicle drivers $[5,6]$. The positive association of young unlicensed drivers involved in fatal crashes in less densely populated areas was demonstrated by a number of studies $[7,8]$.

Concerning reduction of RTIs, the body of evidence supports legislative measures on safety behaviors like helmet use, seat belt use, and compliance to speed limits $[9,10]$. In addition, White et al. [11] argued that legislative measures are less likely to result in an increase in social inequity in health than those of a voluntary behavioral change nature. RTIs in highly motorized countries mostly involve car drivers, whereas they are motorcycle riders in certain countries of Asia, e.g., Thailand and Vietnam $[10,12]$. In contrast to the argument of White et al. [11], legislative measures for helmet use applies only on certain assigned routes and national roads in Vietnam which resulted in 6 times the prevalence on inner-city roads [13].

To address inequity in health, monitoring systems were considered part of actions called upon all governments [14]. Lu et al. [15] demonstrated that after passing a mandatory motorcycle helmet law in 1997, the regional
C Biomed Central

(c) 2013 Suriyawongpaisa et al.; licensee BioMed Central Ltd. This is an Open Access article distributed under the terms of the Creative Commons Attribution License (http://creativecommons.org/licenses/by/2.0), which permits unrestricted use,

distribution, and reproduction in any medium, provided the original work is properly cited. 
inequity in helmet use rate and RTI mortality in Taiwan decreased with a drastic increase in helmet use rate from $45 \%$ to $93 \%$ during 1997 to 2002 before it leveled off then decreased to $88 \% 6$ years later with resurgence in regional inequity in helmet use rate.

Making use of road-side surveys on helmet use, injury sentinel surveillance and other relevant datasets, this report aims to shed some lights on inequity in helmet use and factors associated with it, and the discrepancy between helmet use rates which were estimated by the survey data and the surveillance data in Thailand.

\section{Methods}

\section{Helmet use rate}

We obtained data on helmet use from 2 sources, which were the nationwide roadside survey [16] and injured surveillance data. The latter were maintained by trauma centers which were assigned to be sentinel sites in 26 provinces of 4 geographical regions across the country $[17,18]$.

Detailed sampling design and data analysis for the nationwide roadside survey were presented in ThaiRoads Foundation [16]. Briefly, the nationwide survey, which was undertaken from May to December in 2010, employed direct observations on helmet use among 945,956 randomly selected motorcyclists $(71.4 \%$ of which were drivers). These sampled motorcyclists were identified at 3,252 selected sites comprising locations (i.e., road intersections and road sections), and slow traffic in urban and rural municipalities which varied by sizes. The distribution of the selected sites (as a percentage of the total sites for each category) for large, medium, and small municipalities were respectively as follows: 1276 sites (32.9\%), 560 sites (17.2\%), and 1416 sites (43.5\%). Between provinces, the number of sites varied from 22 to 84 according to the area and number of population. For Bangkok, the capital city with a population of 6.9 million [19], 100 sites were randomly selected from 50 districts ( 2 for each). From this data set, we calculated helmet use rate for the country, each region and each province.

\section{Contextual and helmet use related factors}

Three contextual factors suitable for illustration of disparity in socioeconomic development across provinces were available from the National Socioeconomic and Social Development Board (NESDB). These included percentage of population under poverty lines, gross provincial product (GPP) per capita, and percentage of adult literacy. In addition, two data sets were available for calculating a proxy of traffic law enforcement activities specific to motorcyclists in each province i.e., the number of convicted motorcyclists available from the National Police Office and the accumulated number of registered motorcycles from the Department of Land Transport. Based on the two data sets, we calculated the rate (per 10,000 registered motorcycles) of convicted motorcyclists for each province, hereafter called conviction rate.

\section{Disparity measures}

Health disparity measures are classified into 2 groups, i.e., a relative disparity and an absolute disparity [15]. The relative disparity could be relative concentration index (RCI), rate ratio (RR), and index of disparity (IDisp). The absolute disparity comprised rate difference, between-group variance (BGV), and absolute concentration index (ACI). Each of these measures differs in terms of reference group, whether all individuals in the population are weighted equally, and the scale of measurement of the variable (nominal or ordinal). In practice, making a choice of the disparity measures depends on the availability of data and the scale of measurement.

In this report, we chose highest-to-lowest ratio (HLR) as measures of disparity based on the two practical points and also to allow for comparison with recently published report from Taiwan [15], where their high proportion of motorcycle use was similar to Thailand. To assess disparity in the contextual factors, we calculated the ratio of the highest value to the lowest value. Due to limited space, province specific data were not included but will be available upon request.

\section{Association between contextual factors and helmet use rate}

A cubic spline regression was applied to explore whether relationship between each predictor and the outcome was linear or cubic spline [20]. Data for population density and conviction rate were quite skew and transforming them using natural log-scale also yielded better fit than the raw scales, log-transformation for these 2 variables were thus used. The interested outcome was rate of helmet use whereas the predictors were $\ln$ (conviction rate), $\ln$ (population density), percent under poverty line, adult literacy, and GPP. These predictors were included in the multivariate spline regression with initial degrees of freedom of 4, and the best knot was then identified for each variable. Deviance statistic with backward elimination was applied to select variables in the model. Model assumption of the final model, i.e., normality of residual, was then checked using Shapiro-Wilk test.

\section{Difference between helmet use rate estimated by roadside survey and injury sentinel surveillance}

The rates of helmet use between the two sources of data were compared for each province. An agreement of the two data sources, hereafter called a gap, along with its 95\% confidence interval were estimated using BlandAltman method [21]. 
Table 1 Contextual factors of helmet use by regions in $\mathbf{2 0 1 0}$

\begin{tabular}{lccccccc}
\hline Region & $\begin{array}{c}\text { No. population } \\
(\mathbf{x 1 0 0 0})\end{array}$ & $\begin{array}{c}\text { Poverty } \\
\text { line }\end{array}$ & $\begin{array}{c}\text { \% Under poverty } \\
\text { line }\end{array}$ & $\begin{array}{c}\text { Population } \\
\text { density }\end{array}$ & $\begin{array}{c}\text { GPP per } \\
\text { capital }\end{array}$ & $\begin{array}{c}\text { Adult } \\
\text { literacy }\end{array}$ & $\begin{array}{c}\text { Convicted } \\
\text { motorcyclist }\end{array}$ \\
\hline Bangkok & 6876.7 & 2198 & 8.0 & 1330.4 & $365,619.00$ & 100 & 38.4 \\
Central & 640.1 & 1725.4 & 32.6 & 314.8 & $246,301.00$ & 99.7 & 9.2 \\
North & 716.2 & 1572.8 & 39.8 & 73.5 & $78,315.60$ & 98.1 & 6.3 \\
Northeast & 1167.2 & 1582.7 & 50.9 & 132 & $48,292.10$ & 99.8 & 6.5 \\
South & 669.9 & 1627 & 22.6 & 146.1 & $113,406.00$ & 99.3 & 5.9 \\
Inequity across & & & & & & & \\
provinces & & & 597.70 & & & & \\
HLR & & & & & & & \\
\hline
\end{tabular}

All statistical analyses were performed using STATA version 12.0. A p value $<0.05$ was considered as statistical significance.

\section{Results}

Table 1 has described relative (HLR) disparity of contextual factors across provinces with relevant figures for each region including Bangkok, the capital city. These included percentage of population under poverty lines, percentage of adult literacy, and rate per 10,000 of convicted motorcyclists (conviction rate). The percentage of population under poverty lines have the biggest magnitude (HLR $=597.70)$. The next big gap was the conviction rate $(\mathrm{HLR}=87.24)$. Disparity of GPP per capita was shown in relative measure with a ratio of 29.20 between the province with the highest GPP and that with the lowest. The smallest gap was in adult literacy rate $(\mathrm{HLR}=1.04)$.

Table 2 has depicted differences in helmet use rate with 95\% CI among combined groups of drivers and passengers and in separated groups across provinces. Helmet use rate was found highest $(81.8 \%)$ in Bangkok for all types of riders. The relative provincial disparity was highest in passengers (HLR=28.5).

Helmet use rates based on injuries sentinel surveillance data set in 2010 (available for 26 provincial sentinel sites) and that from the survey in corresponding provinces were compared, see Table 3. This suggested a gap of $34.29 \%$ (95\% CI: $13.48,55.09$ ), indicating that the injuries sentinel surveillance data approximately $34 \%$ under estimated the use of helmets when compared with the survey data. In addition, the correlation of the two data sets was poor with the estimated correlation coefficient of 0.218 (p-value 0.285 ).

We assessed association between contextual factors and helmet use rate, as described in Table 4.

Among 5 predictors (i.e., $\ln$ (conviction rate), $\ln (\mathrm{popu}-$ lation density), percent of population under poverty lines, GPP, and adult literacy), only 2 significant predictors (i.e., $\ln$ (conviction rate) and $\ln$ (population density) were kept in the final model as for a process of model selection. This model met an assumption of normality of residual, which was explored using Shapiro-Wilk test $(\mathrm{Z}=1.58, \mathrm{p}=0.056)$.

Our model suggested that the $\ln$ (conviction rate) was linearly correlated with helmet use rate $(t=2.27$, $\mathrm{p}=0.026)$ by increasing 1 unit of $\ln$ (conviction rate) would increase helmet use rate of $3.9 \%$. Association between $\ln$ (population density) and helmet use was also linear, by increasing 1 unit of $\ln ($ population density) could increase rate of helmet by $6.8 \%$.

Table 2 Prevalence (\%) of helmet use by geographical regions and rider positions including HLR across provinces in 2010

\begin{tabular}{|c|c|c|c|c|c|c|c|c|c|}
\hline Region & Drivers and passengers & $\mathrm{N}$ & $95 \% \mathrm{Cl}$ & Drivers & $\mathbf{N}$ & $95 \% \mathrm{Cl}$ & Passengers & $\mathrm{N}$ & $95 \% \mathrm{Cl}$ \\
\hline Bangkok & 81.8 & 27,647 & $81.3,82.2$ & 93.2 & 21,062 & $92.8,93.5$ & 45.2 & 6,585 & $44.0,46.4$ \\
\hline North & 37.4 & 150,888 & $37.2,37.7$ & 44.8 & 109,735 & $44.5,45.1$ & 17.2 & 41,153 & $16.8,17.5$ \\
\hline North East & 38.4 & 247,821 & $38.2,38.6$ & 47.6 & 169,017 & $47.3,47.8$ & 19.8 & 78,804 & $19.5,20.0$ \\
\hline Central & 53.5 & 317,301 & $53.2,53.8$ & 63.9 & 228,852 & $63.7,64.1$ & 24.4 & 88,449 & $23.7,25.1$ \\
\hline South & 36 & 238,946 & $35.8,36.2$ & 47 & 167,675 & $46.7,47.2$ & 9.4 & 71,271 & $9.2,9.6$ \\
\hline Nationwide & 43.7 & 954,956 & $43.6,43.9$ & 53.3 & 675,279 & $53.2,53.8$ & 19.3 & 279,677 & $18.9,19.7$ \\
\hline \multicolumn{10}{|c|}{ Inequality across provinces } \\
\hline HLR & 5.5 & & & 4.4 & & & 28.5 & & \\
\hline
\end{tabular}


Table 3 Comparison of \% helmet use from survey and sentinel injury surveillance in 2010 by province

\begin{tabular}{|c|c|c|c|c|c|c|c|c|c|c|c|c|}
\hline \multirow[t]{2}{*}{ Province } & \multicolumn{3}{|l|}{ Male } & \multicolumn{3}{|l|}{ Female } & \multicolumn{3}{|l|}{ Teen } & \multicolumn{3}{|l|}{ Adult } \\
\hline & Survey & IS & Diff & Survey & IS & Diff & Survey & IS & Diff & Survey & IS & Diff \\
\hline Ayutthaya & 41.87 & 12.85 & 29.02 & 21.65 & 13.55 & 8.10 & 26.50 & 11.26 & 15.24 & 39.4 & 13.57 & 25.81 \\
\hline Saraburi & 57.90 & 17.49 & 40.41 & 38.24 & 11.03 & 27.21 & 33.36 & 10.08 & 23.28 & 60.4 & 17.42 & 42.98 \\
\hline Chonburi & 53.09 & 1.89 & 51.20 & 40.02 & 1.95 & 38.07 & 32.78 & 0.87 & 31.91 & 56.5 & 2.21 & 54.33 \\
\hline Rayong & 45.33 & 16.81 & 28.52 & 29.85 & 14.73 & 15.12 & 26.02 & 8.72 & 17.30 & 46.4 & 18.25 & 28.12 \\
\hline Chanthaburi & 35.58 & 14.61 & 20.97 & 27.61 & 19.62 & 7.99 & 21.20 & 5.32 & 15.88 & 39.3 & 18.56 & 20.70 \\
\hline Prachinburi & 29.23 & 15.73 & 13.50 & 20.98 & 17.31 & 3.67 & 18.32 & 11.82 & 6.50 & 32.1 & 17.37 & 14.71 \\
\hline Nakhonratchasima & 52.05 & 25.93 & 26.12 & 42.93 & 31.65 & 11.28 & 38.28 & 17.29 & 20.99 & 58.7 & 31.27 & 27.44 \\
\hline Surin & 59.22 & 9.99 & 49.23 & 39.61 & 18.99 & 20.62 & 43.37 & 7.88 & 35.49 & 70.0 & 14.1 & 55.90 \\
\hline Ubornratchathani & 49.90 & 13.69 & 36.21 & 32.99 & 23 & 9.99 & 34.27 & 11.87 & 22.40 & 49.0 & 17 & 31.98 \\
\hline Khonkaen & 54.18 & 11.93 & 42.25 & 11.88 & 16.04 & -4.16 & 14.28 & 7.02 & 7.26 & 50.3 & 15.04 & 35.31 \\
\hline Udornthani & 46.13 & 4.8 & 41.33 & 10.71 & 8.8 & 1.91 & 16.19 & 4.55 & 11.64 & 42.2 & 6.2 & 35.97 \\
\hline Lampang & 44.85 & 8.45 & 36.40 & 47.94 & 17.35 & 30.59 & 29.28 & 7.08 & 22.20 & 55.1 & 11.7 & 43.37 \\
\hline Uttaradit & 39.73 & 10.85 & 28.88 & 42.17 & 19.38 & 22.79 & 30.60 & 10.1 & 20.50 & 48.7 & 14.16 & 34.50 \\
\hline Chiangrai & 40.09 & 4.51 & 35.58 & 30.28 & 9.09 & 21.19 & 27.90 & 2.39 & 25.51 & 41.3 & 6.62 & 34.69 \\
\hline Nakhonsawan & 55.37 & 15.61 & 39.76 & 41.05 & 17.45 & 23.60 & 41.56 & 10.63 & 30.93 & 53.0 & 17.8 & 35.20 \\
\hline Phitsanulok & 51.41 & 11.68 & 39.73 & 49.63 & 21.01 & 28.62 & 45.47 & 9.55 & 35.92 & 56.5 & 15.32 & 41.14 \\
\hline Ratchaburi & 31.98 & 2.53 & 29.45 & 22.91 & 3.42 & 19.49 & 21.45 & 2.66 & 18.79 & 35.8 & 2.85 & 32.93 \\
\hline Suphanburi & 34.74 & 1.48 & 33.26 & 24.57 & 2.9 & 21.67 & 23.36 & 0.7 & 22.66 & 35.3 & 2.18 & 33.10 \\
\hline Nakhonpathom & 41.28 & 13.32 & 27.96 & 22.05 & 12.64 & 9.41 & 19.69 & 3.53 & 16.16 & 43.1 & 16.23 & 26.85 \\
\hline Nakhonsithammarat & 42.16 & 12.29 & 29.87 & 29.09 & 14.82 & 14.27 & 16.50 & 6.99 & 9.51 & 44.7 & 15.34 & 29.40 \\
\hline Suratthani & 37.28 & 9.66 & 27.62 & 31.31 & 12 & 19.31 & 24.60 & 6.98 & 17.62 & 41.9 & 11.75 & 30.17 \\
\hline Songkhla & 45.51 & 20.14 & 25.37 & 33.75 & 21.68 & 12.07 & 30.77 & 9.6 & 21.17 & 45.0 & 24.75 & 20.25 \\
\hline Trang & 50.61 & 8.83 & 41.78 & 33.21 & 10.9 & 22.31 & 26.15 & 4.89 & 21.26 & 51.7 & 11.29 & 40.40 \\
\hline Yala & 25.60 & 3.25 & 22.35 & 25.95 & 3.37 & 22.58 & 13.61 & 1.31 & 12.30 & 30.9 & 4.14 & 26.79 \\
\hline Nonthaburi & 69.60 & 5.29 & 64.31 & 40.81 & 1.16 & 39.65 & 44.41 & 4 & 40.41 & 71.3 & 4.64 & 66.67 \\
\hline Chachengsoa & 36.93 & 6.54 & 30.39 & 21.13 & 5.47 & 15.66 & 18.86 & 2.88 & 15.98 & 36.5 & 7.3 & 29.15 \\
\hline overall & & & 34.29 & & & 17.81 & & & 20.72 & & & 34.53 \\
\hline $95 \%$ limiits of agreem & ent* & & $13.48,55.09$ & & & $-2.76 ; 38.36$ & & & $3.69,37.76$ & & & $12.13,56.95$ \\
\hline rho_c** & & & 0.218 & & & 0.332 & & & 0.401 & & & 0.215 \\
\hline p-value of rho_c & & & 0.285 & & & 0.097 & & & 0.042 & & & 0.292 \\
\hline
\end{tabular}

*Bland \& Altman; **Concordance correlation coefficient.

\section{Discussion}

After passage of motorcycle helmet laws for drivers in 1994 and for passengers in 2007 in Thailand, this report revealed helmet use rate of $43.7 \%$ nationwide with the highest rate $(81.8 \%)$ in Bangkok. Helmet use rate in drivers was almost 3 times higher than that in passengers (19.3\%). Disparity in helmet use across provinces

Table 4 Factors associated with helmet use rate according to spline regression analysis

\begin{tabular}{lcccccc}
\hline Use of helmet & Coefficient & SE & $\mathbf{t}$ & $\mathbf{P}>|\mathbf{t}|$ & \multicolumn{2}{c}{$\mathbf{9 5 \%} \mathbf{C l}$} \\
\hline Conviction rate & 3.90 & 1.72 & 2.27 & 0.026 & 0.48 & 7.33 \\
Population density & 6.77 & 1.49 & 4.55 & $<0.001$ & 3.81 & 9.74 \\
\hline
\end{tabular}

was found highest among passengers (HLR=28.5). The provincial disparity in 2010 of helmet use in this report was 3 times bigger than that reported in 2008 in Taiwan [15]. The helmet use rate of $88 \%$ in Taiwan in 2008 was twice the rate $(43.7 \%)$ of our study in Thailand. A plausible explanation of these observations is the difference in level of traffic law enforcement between the two countries.

The bigger disparity of helmet use in passengers as compared to that of drivers corresponded with more recent enactment of motorcycle helmet use law for passengers in 2007 than that in 1994 for drivers [22]. Evans indicated larger police forces dedicated to traffic law enforcement were associated with improved automobile 
driver behaviors [23]. In our study, we found evidence supporting this notion which was indicated by spline regression coefficient of provincial helmet use rate and level of provincial traffic law enforcement represented by $\ln$ (conviction rate) of 3.9 (95\% CI : 0.48,7.33). (see Table 4). In addition, $\ln$ (population density) was associated with helmet use rate with a coefficient of 6.77 $(95 \% \mathrm{CI}: 3.81,9.74)$. Hence, it follows that traffic law enforcement is more feasible in areas with more dense population which facilitates spatial distribution of limited number of police forces.

Considering the disparity in conviction rate across provinces together with the association between the conviction rate/population density and helmet use rate, more equitable improvement in helmet use could be achieved by more equitable distribution of the police force.

This report found no significant association between adult literacy and helmet use rate (see Table 4). This finding could be due to the facts that the relatively low price of motorcycles comparing to 4-wheelers, and the majority of motor vehicles are motorcycles owned by relatively low income households.

This report indicated a big gap ( 28\%) and poor correlation in helmet use rate between the two sources of data i.e., roadside survey and injury sentinel surveillance. As a result, the injury sentinel surveillance may under estimate the rate of helmet use. This might be due to insufficient funding for sentinel injury surveillance to maintain the quality assurance of data collection [24]; although standardized and uniform hospital data formats have been used since inception of the surveillance [17]. Another explanation is the injury surveillance was mainly focused on hospitalized cases which were more severely injured than non- hospitalized cases indicating a higher probability of not wearing helmet among hospitalized cases [12].

Finally, it is worth mentioning about some limitations of the study. Using cross sectional data, it is difficult to draw a causal association between helmet use rate and those contextual factors found in this report. Although spline regression analysis was applied to test the associations controlling for confounding factors, other known confounding factors such as over speeding, drink driving were not included. Further studies, hence, are needed to better test causal association between helmet use rate and potential predictors.

\section{Conclusions}

Using national representative roadside survey data on helmet use enables us to better demonstrate the disparity in helmet use across provinces as compared to a previous study in Taiwan [15] which relied on hospitalbased injury surveillance dataset. We were also able to explore the provincial disparity of helmet use by riding status. With access to national data sets on traffic law policing and socioeconomic status, we were able to explore the potential relationship between helmet use rate and selected contextual factors i.e., conviction rate of motorcyclists, population density, GPP per capita and percentage of residents under poverty line. Finally, we were able to test agreement and correlation between helmet use rate reported by the roadside survey and sentinel injuries surveillance. To the beat of our knowledge, these findings are quite novel.

To achieve equitable and effective allocation of resources for promoting motorcycle helmet use, a country needs to monitor geographical and demographic distribution of the behaviors in the long term. Periodic roadside survey might be considered a monitoring tool for motorcycle helmet use in countries without reliable injury surveillance data, which requires sufficient long term investment.

\section{Competing interests}

The authors declare that they have no competing interests.

\section{Authors' contributions}

PS drafted the first manuscript and compiled all secondary data sets. AT conducted statistical analyses of the data and reviewed the first draft. AR and PT provided accessed to the injury surveillance data and reviewed the first draft. PJ provided accessed to the roadside survey data and reviewed the first draft. All authors read and approved the final manuscript.

\section{Authors' information}

Paibul Suriyawongpaisal is an epidemiologist working on road safety policy at national scale for over 2 decades. Ammarin Thakinsatien is a $\mathrm{PhD}$ graduate in health statistics with a decade of experiences in applying multivariate analytical methods. Aratta Rangpueng and Pimpa Techakamolsuk are key persons responsible for maintaining the injury surveillance data set at the Ministry of Public Health. Piyapong Jiwattanakulpaisarn has been the principal investigator of the national roadside survey on helmet use conducted annually since 2010.

\section{Author details}

${ }^{1}$ Department of Community Medicine, Faculty of Medicine, Ramathibodi Hospital, Mahidol University, Rama VI, Ratchathevee 10400, Thailand. Section for Clinical Epidemiology and Biostatistics, Faculty of Medicine, Ramathibodi Hospital, Mahidol University, Rama VI, Ratchathevee, Bangkok 10400, Thailand. ${ }^{3}$ Department of Diseases Control, Ministry of Public Health, Tiwanon, Muang District, Nonthaburi 11000, Thailand. ${ }^{4}$ ThaiRoads Foundation, Radploa Rd, Jatujak, Bangkok 10900, Thailand.

Received: 20 May 2013 Accepted: 21 July 2013

Published: 30 August 2013

\section{References}

1. World Health Organization: Global status report on road safety 2013: supporting a decade of action. Geneva: World Health Organization; 2013.

2. US Centers for Disease Control: Weekly Motor vehicle-related death rates-United States, 1999-2005. Morbidity and Mortality Weekly Report (MMWR) 2009, 58(07):161-165.

3. Yongchaitrakul T, Juntakarn C, Prasartritha T: Socioeconomic inequality and road traffic accidents in Thailand: comparing cases treated in government hospitals inside and outside of Bangkok. Southeast Asian J Trop Med Public Health 2012, 43(3):785-794.

4. Hanna $C L$, Laflamme L, Bingham CR: Fatal crash involvement of unlicensed young drivers: county level differences according to material deprivation and urbanicity in the United States. Accid Anal Prev 2012, 45(Mar):291-295. 
5. La Torre G, Van Beeck E, Quaranta G, Mannocci A, Ricciardi W: Determinants of within-country variation in traffic accident mortality in Italy: a geographical analysis. Int J Health Geogr 2007, 6:49.

6. Rivas-Ruiz F, Perea-Milla E, Jiminez-Puente A: Geographic variability of fatal road traffic injuries in Spain during the period 2002-2004: an ecological study. BMC Publ Health 2007, 7:266.

7. Kallail KJ, Johnston SC, Melhorn KJ, Boyce MC, Golbeck AL, Frisch LE: The influence of license status on Kansas child fatalities due to motor vehicles. Internal J Injury Control and Safety Promotion 2008, 15(2):77-82.

8. Peek-Asa C, Britton C, Young T, Pawlovich M, Falb S: Teenage driver crash incidence and factors influencing crash injury by rurality. J Safety Res 2010, 41(6):487-492.

9. Ameratunga S, Hijar M, Norton R: Road-traffic injuries: confronting disparities to address a global-health problem. Lancet 2006, 367:1533-1540.

10. World Health Organization: Helmets: a road safety manual for decision makers and practitioners. Geneva: World Health Organization; 2006.

11. White $M$, Adams J, Heywood P: How and why do interventions that increase health overall widen inequalities within population? In From equity to health: international and interdisciplinary perspectives on the link between social inequality and human health. Edited by Babones S. Nashville: Vanderbilt University Press; 2008.

12. Suriyawongpaisal $P$, Kanchanasut $S$ : Road traffic injuries in Thailand: trends, selected underlying determinants and status of intervention. Inj Control Saf Promot 2003, 10(1-2):95-104.

13. Hung DV, Stevenson MR, Ivers RQ: Prevalence of helmet use among motorcycle riders in Vietnam. Inj Prev 2006, 12(6):409-413.

14. Commission on Social Determinants of Health: Final Report of the Commission on Social Determinants of Health. Geneva: World Health Organization; 2008

15. Lu TH, Lai CH, Chiang TL: Reducing regional inequality in mortality from road traffic injuries through enforcement of the mandatory motorcycle helmet law in Taiwan. Inj Prev 2012, 18:150-157.

16. ThaiRoads Foundation: Helmet use rate of motorcyclists in Thailand B.E.2553. Bangkok; 2011.

17. Santikarn C, Punyaratanabandhu P, Podhipak A, Rukronayut K, Sujirarat D, Wiengpitak S, Pichainarong $\mathrm{N}$ : The establishment of injury surveillance in Thailand. Int J Consumer Product Safety 1999, 6(3):133-143(11).

18. Podang J, Singhasivanon P, Podhipak A, Santikarn C, Sarol JN Jr, Ancheta CA: Primary verification: is the TRISS appropriate for Thailand? Southeast Asian J Trop Med Public Health 2004, 35:188-194.

19. Office of the National Economic and Social Development Board: Social and quality of life database system, Estimated annual number of population by sex and province for the year 2000-2020; 2013. Available at http://social.nesdb.go.th (accessed 8 January 2013).

20. Royston P: Choice of scale for cubic smoothing spline models in medical applications. Stat Med 2000, 19(9):1191-1205.

21. Bland JM, Altman DG: Statistical methods for assessing agreement between two methods of clinical measurement. Lancet 1986(i):307-310.

22. Legislative Institutional Repository of Thailand: Land Traffic Control Act 2007; 2013. Available at http://dl.parliament.go.th/handle/lirt/16871? show=full (accessed 5 March 2013).

23. Evans L: Traffic safety. Bloomfield Hills, MI: Science Serving Society; 2004.

24. Nwomeh BC, Lowell W, Kable R, Haley K, Ameh EA: History and development of trauma registry: lessons from developed to developing countries. World J Emergency Surgery 2006, 1:32.

\section{Submit your next manuscript to BioMed Central and take full advantage of:}

- Convenient online submission

- Thorough peer review

- No space constraints or color figure charges

- Immediate publication on acceptance

- Inclusion in PubMed, CAS, Scopus and Google Scholar

- Research which is freely available for redistribution

Submit your manuscript at www.biomedcentral.com/submit
Ciomed Central 